Yüzüncü Yil Üniversitesi
Tarim Bilimleri Dergisi

Araştırma Makalesi (Research Article)

\title{
Türkiye'de Yetişen Bazı Apiaceae Türlerinin Uçucu Yağlarının Kök Lezyon Nematodlarına Karşı Nematisidal Aktiviteleri
}

\author{
Fatma Gül GÖZE ÖZDEMIR ${ }^{* 1}$, Bekir TOSUN ${ }^{2}$, Arif ŞANLI ${ }^{3}$, Tahsin KARADOĞAN ${ }^{4}$ \\ ${ }^{1}$ Isparta Uygulamalı Bilimler Üniversitesi, Ziraat Fakültesi, Bitki Koruma Bölümü, Isparta, Türkiye \\ ${ }^{2}$ Burdur Mehmet Akif Ersoy Üniv., Tarım, Hayvancılık ve Gıda Araş. Uyg. ve Araş. Merkezi, Burdur, Türkiye \\ ${ }^{3-4}$ Isparta Uygulamalı Bilimler Üniversitesi, Ziraat Fakültesi, Tarla Bitkileri Bölümü, Isparta, Türkiye \\ ${ }^{1}$ https://orcid.org/0000-0003-1969-4041 2https://orcid.org/0000-0002-2470-3865 3https://orcid.org/0000-0002-3422-8295 \\ ${ }^{4}$ https://orcid.org/0000-0002-5443-2082 \\ *Sorumlu yazar e-posta: btosun@mehmetakif.edu.tr
}

\section{Makale Bilgileri}

Geliș: 18.09 .2020

Kabul: 10.04.2021

Online Yayınlanma 30.06.2021

DOI: 10.29133/yyutbd.796093

Anahtar kelimeler

Apiaceae,

Nematisidal etki,

Pratylenchus spp.,

Uçucu yağ.
Öz: Çalışmada Türkiye doğal florasında yetişen Apiaceae familyasına ait 12 farklı bitki türünün uçucu yağının Kök lezyon nematodlarına (Pratylenchus penetrans, $P$. thornei ve $P$. neglectus) karşı nematisidal etkileri incelenmiştir. Araştırma in vitro koşullarda yürütülmüş̧ olup, her bir uçucu yağın 1000 ppm konsantrasyonu kullanılmıştır. Uçucu yağların nematisidal etkileri Kök lezyon nematodu türüne bağlı olarak değişiklik göstermiş, $P$. neglectus türünde Coriondrum sativum L., $P$. thornei türünde Ferulago cassia Boiss, $P$. penetrans türünde ise Foeniculum vulgare Miller ve Anethum graveolens L. uçucu yağları diğer uygulamalardan daha yüksek etkinlik göstermiş̧tir. Uçucu yağ uygulamalarına bağlı olarak gerçekleşen nematod ölüm oranları $P$. neglectus türünde $\%$ 24.3-64.7, $P$. penetrans türünde $\%$ 23.7-66.7 ve $P$. thornei türünde $\%$ 33.7-85.0 arasında bulunmuştur. Araştırmada, uçucu yağ aktif maddelerinden linalool, phallendrene ve 2,3,6 trimetilbenzaldehyde bileşenlerini içeren bitkilerin yüksek, anethole ve carvone bileşenlerini içeren bitkilerin orta, caratol ve curzerene bileşenlerini içerenlerin ise düşük nematoksik aktivite gösterdiği anlaşılmış̧ır. Apiaceae familyası türlerinin Pratylenchus türlerine karşı nematisidal etkilerinin yüksek fakat değişken olduğu, bu nedenle yüksek aktivite gösteren uçucu yağların farklı dozlar kullanılarak arazi koşullarında etkinliklerinin denenmesi ile daha kesin sonuçlara ulaşılabileceği anlaşılmıştır.

\section{Nematicidal Activity of Essential Oils from Apiaceae Family Plants of Turkey Against Root Lesion Nematodes}

\section{Article Info}

Received: 18.09 .2020

Accepted: 10.04.2021

Online Published 30.06.2021

DOI: 10.29133/yyutbd.796093

\section{Keywords}

Apiaceae,

Nematicidal effect,

Pratylenchus spp.,

Essential oil.

\begin{abstract}
In our study, the nematicidal activity of 12 essential oils from Apiaceae family plants of Turkey against Pratylenchus penetrans, P. thornei and $P$. neglectus root lesion nematodes were investigated. The study was conducted in vitro conditions and concentration of $1000 \mathrm{ppm}$ of each essential oil was used. The nematicidal effect was found to depending on root lesion nematode species and high nematicidal effect were found $P$. neglectus species; Coriondrum sativum L., P. thornei species; Ferulago cassia Boiss and $P$. penetrans Foeniculum vulgare Miller and Anethum graveolens L. Mortality rates depending on essential oil applications varied between $24.3-64.7 \%$ in $P$. neglectus species, $23.7-66.7 \%$ in $P$. penetrans and $33.7-85.0 \%$ in $P$. thornei. In this study, the nematicidal activity were found high that essential oil active ingredients of plants containing linalool, phallendrene and 2,3,6
\end{abstract}


trimethylbenzaldehyde components while the plants containing anethole and carvone components were medium nematicidal activity and containing caratol and curzerene components showed low. It has been understood that the nematicidal activity of Apiaceae family species against Pratylenchus species are high but variable, therefore, more definite results can be achieved by testing the effectiveness of highly active essential oils using different doses in field conditions.

\section{Giriş}

Kök lezyon nematodları (Pratylenchus spp.) bitkilerde en çok zarar yapan paraziti nematod gruplarından biri olup, dünyada yaygın olarak görülmektedir. Kök lezyon nematodlarının konukçu dizilerinde geniş çeşitlilik (meyveler, sebzeler ile tarla bitkilerinde) görülmesinin yanı sıra önemli ekonomik kayıplara neden olabilmektedirler. Kök lezyon nematodlarının hücre içi hareketi kortikal ve komşu hücrelerin ölümüne neden olmakta, membran bütünlüğünü kaybetmekte, hücrelerin organelleri dejenere olmakta ve sonucunda kökte kahverengi lekeler oluşmaktadır (Castillo ve Vovlas, 2007). Bununla birlikte birçok toprak kökenli hastalık ve zararlı etmeninin bitkiye giriş yapmasına yardımcı olmaları sonucu üründe dolaylı olarak ekonomik kayıplara neden oldukları bilinmektedir (Smiley ve Nicol, 2009). Pratylenchus penetrans (Cobb, 1917) Filipjev\&Schuurmans Stekhoven, 1941, Pratylenchus thornei Sher \& Allen, 1953, Pratylenchus neglectus (Rensch, 1924) Filipjev\&Schuurmans Stekhoven, 1941, Pratylenchus brachyurus (Godfrey, 1929) Filipjev\&Schuurmans Stekhoven, 1941, Pratylenchus coffeae (Zimmermann, 1898) Filipjev\&Schuurmans Stekhoven, 1941, Pratylenchus goodeyi Sher\&Allen, 1953, Pratylenchus loosi Loof, 1960, Pratylenchus pratensis (de Man, 1880) Filipjev, 1936, Pratylenchus scribneri Steiner Sherbakoff\&Stanley, 1943, Pratylenchus vulnus Allen\&Jensen, 1951 ve Pratylenchus zeae Graham, 1951 ekonomik anlamda önemli zarar yapan türler arasında gösterilmektedir (Blair ve Stirling, 2007; Jones ve Fosu-Nyarko, 2014).

Kök lezyon nematodları ile mücadelede yaygın kullanılan yöntemler sentetik fümigantlar, nematisitler ve dayanıklı çeşit seçimidir. Nematisitlerin neden olduğu çevre sorunları, 1sıl işlemlerin maliyeti ve dayanıklı çeşitlerin sınırlı sayıda olması, nematod mücadelesini biyolojik kontrol ve doğal ürünler gibi daha ekolojik alternatif yöntemlere doğru yöneltmektedir. Bazı bitki türlerinde doğal olarak sentezlenen alkoloidler, fenolik bileşikler, terpenoidler ve glikozitler gibi bazı sekonder metabolitler nematodlarla mücadelede sürdürülebilir alternatif bir yol sunmaktadır. Sekonder metabolitlerin terpenoidler grubunda yer alan uçucu yağlar, farklı yapı ve özellikte biyolojik aktif madde içermeleri nedeniyle sentetik nematisitlere alternatif olabilecek potansiyele sahip bileşiklerdendir. Uçucu yağların hedef alınmayan organizmalara düşük toksisiteye sahip olmalarının yanı sıra uygulandıkları ortamdan çabuk kaybolma özellikleri ile çevrede birikimleri ve kalıntı miktarları çok düşüktür (Figueiredo ve ark., 2008). Uçucu yağlar karmaşık yapıları sayesinde aynı zamanda firsatçı türleri ve dirençli suşları da kontrol edebilme gibi çeşitli biyolojik aktiviteler gösterebilmekte ve bu etki, uçucu yağların biyopestisit olarak değerlendirilme olanaklarını arttırmaktadır. Apiaceae familyanın önemli bir kısmı uçucu yağ, fenolik bileşikler ve kumarinler bakımından zengin olup tıbbi ve aromatik kullanımlarının dışında antimikrobiyal, antiviral, antifungal, nematisidal, insektisidal ve antioksidan gibi özellikler gösterebilmektedirler (Dorman ve Deans, 2000; Cavanagh, 2007; Ntalli ve ark., 2010; Lang ve Buchbauer, 2012).

Uçucu yağ kaynaklı ticari nematisitler piyasada henüz görünmüyorsa da, bitki paraziti nematodlar ile mücadelede başarı şansının artırılabilmesi için uçucu yağ formülasyonlarına dayalı yeni ürünlerin geliştirilmesi kaçınılmaz olarak görülmektedir (Renco ve ark., 2015). Nitekim Brassicaceae, Lamiaceae, Asteraceae, Myrtaceae, Rutaceae, Lauraceae ve Poaceae familyalarında yer alan bazı bitkilerin uçucu yağlarının nematisidal aktiviteye sahip olduğu daha önceki araştırmalarda ortaya konulmuştur (Andres ve ark., 2012). Uçucu yağ bileşenleri, nematod sinir sistemine etki ettiği gibi nematodun hücre zarını bozabilmekte ve geçirgenliğini değiştirebilmektedir (Oka ve ark., 2000). Apiaceae familyasına ait bazı uçucu yağların (Carum capticum, Carum carvi, Foeniculum vulgare ve Pimpinella anisum) kök-ur nematodu Meloidogyne incognita (Kofoid ve White, 1919) ve Meloidogyne javanica (Treub, 1885) üzerinde nematisidal etkiye sahip olduğu bildirilmiştir (Oka ve ark., 2000; Gupta ve ark., 2011; Ntalli ve ark., 2011). Calvet ve ark. (2001), P. brachyurus kök lezyon 
nematodu üzerine $F$. vulgare uçucu yağının yüksek nematisit etkisi olduğunu, benzaldehit, salisilaldehit, borneol, p-anisaldehit ve cinnamaldehyde gibi uçucu bileşiklerin $P$. brachyurus türünde \% 50'den fazla ölüme neden olduğunu bildirmişlerdir. Avato ve ark. (2017), in vitro koşullarda 15 $\mathrm{mg} / \mathrm{ml}$ Rosmarinus officinalis uçucu yağı uygulamasında 96 saat sonra $P$. vulnus ölüm oranının \% 75'e yükseldiğini bildirmişlerdir. Uçucu yăg ve aktif maddelerinin Kök ur nematodlarına etkileri konusunda çok sayıda araştırma yapılmış olmakla birlikte, bu çalışmada kullanılan türlerin ve içerdikleri aktif maddelerin önemli bir kısmının nematisidal etkisi hakkında herhangi bir çalışmaya rastlanmamıştır. Ayrıca, bu çalışmada kullanılan uçucu yağ bitkilerinin önemli bir kısmının doğal florada yetişen türler olması ve bu türlere ilişkin çalışma bulunmaması da çalışmanın özgünlügünnü ortaya koymaktadır.

Çalışmada ülkemizde kültürü yapılan Apiaceae familyasına ait bazı bitki türlerinin (Anethum graveolens L., Coriondrum sativum L. ve Pimpinella anisum L.,) ve doğal florada bulunan (Ferulago pauciradiata Boiss\&Held (Endemik), Foeniculum vulgare Miller., Ferulago cassia Boiss, Daucus carota L., Angelica sylvestris L., Scandix iberica Bieb., Kundmannia anatolica Boiss (Endemik), Heracleum platytaenium Boiss.(Endemik), Smyrnium connatum Boiss\&Kotschy) uçucu yağlarının Kök lezyon nematodlarına ( $P$. penetrans, $P$. thornei ve $P$. neglectus) karş1 nematoksik etkilerinin belirlenmesi ve doğal nematisit olarak kullanılabilme potansiyellerinin belirlenmesi amaçlanmıştır.

\section{Materyal ve Yöntem}

\subsection{Materyal}

Çalışma 2018 yılında in vitro koşullarda yürütülmüştür. Çalışmada kullanılan Kök lezyon nematodları ( $P$. penetrans, $P$. thornei ve $P$. neglectus) daha önce bölgemizde yürütülen çalışma sonucunda tanımlanan türlerden (Söğüt ve Devran 2011), bitki materyalleri ise TÜBİTAK 113O284 nolu projeden (Çizelge 1) temin edilmiştir.

Çizelge 1. Çalışmada kullanılan bitki türleri ve türlere ait meyve uçucu yağlarını oluşturan önemli bileşenler

\begin{tabular}{|c|c|c|c|c|}
\hline Apiaceae Türleri & S.M. Grubu & Ana Bileşenler (\%) & & \\
\hline Anethum graveolens L. & Monoterpen & $\begin{array}{l}\text { d-Carvone } \\
\text { (\% 51.7) }\end{array}$ & $\begin{array}{l}\text { L-Limonene } \\
\text { (\% 24.8) }\end{array}$ & $\begin{array}{l}\text { Dihydrocarvone } \\
\text { (\% 6.3) }\end{array}$ \\
\hline Angelica sylvestris L. & Monoterpen & $\begin{array}{l}\beta \text { - Phellandrene } \\
(\% \text { 29.6) }\end{array}$ & $\begin{array}{l}\text { L- Phellandrene } \\
\text { (\% 16.0) }\end{array}$ & $\begin{array}{l}\text { Bicyclogermacrene (\% } \\
\text { 10.4) }\end{array}$ \\
\hline Coriondrum sativum L. & Monoterpen & $\begin{array}{l}\text { Linalool } \\
(\% 56.3)\end{array}$ & $\begin{array}{l}\alpha \text {-pinene } \\
(\% \text { 10.0) }\end{array}$ & $\begin{array}{l}\text { Geranyl acetate } \\
(\% 9.6)\end{array}$ \\
\hline Daucus carota Linne & Seskiterpen & $\begin{array}{l}\text { Caratol } \\
(\% 42.6)\end{array}$ & $\begin{array}{l}\gamma \text { - Cadinene } \\
(\% 12.8)\end{array}$ & $\begin{array}{l}\beta \text {-Farnesene } \\
(\% \text { 8.82) }\end{array}$ \\
\hline Ferulago cassia Boiss. & Aldehit & $\begin{array}{l}\text { Mesitaldehyde } \\
\text { (\% 25.5) }\end{array}$ & $\begin{array}{l}\text { Chrysanthenyl } \\
\text { Acetate (\% 19.3) }\end{array}$ & $\begin{array}{l}\alpha \text {-pinene } \\
(\% \text { 12.1) }\end{array}$ \\
\hline $\begin{array}{l}\text { Ferulago pauciradiata } \\
\text { Boiss \& Heldr }\end{array}$ & Monoterpen & $\begin{array}{l}\text { Epiglobulol } \\
(\% \text { 8.4) }\end{array}$ & $\begin{array}{l}\alpha \text {-pinene } \\
\text { (\% 7.8) }\end{array}$ & $\begin{array}{l}\text { Ar-Crucumene } \\
(\% 7.8)\end{array}$ \\
\hline Foeniculum vulgare Miller & Monoterpen & $\begin{array}{l}\text { Trans anethole } \\
(\% 75.4)\end{array}$ & $\begin{array}{l}\text { L-Limonene } \\
\text { (\% 9.06) }\end{array}$ & $\begin{array}{l}\text { p-Allylanisole } \\
\text { (\% 7.78) }\end{array}$ \\
\hline $\begin{array}{l}\text { Heracleum platytaenium } \\
\text { Boiss. }\end{array}$ & Ester & $\begin{array}{l}\text { Octyl Butyrate } \\
\text { (\% 38.5) }\end{array}$ & $\begin{array}{l}\text { Ethylhexyl Acetate } \\
\text { (\% 27.6) }\end{array}$ & $\begin{array}{l}\text { Hexyl Butanoate } \\
(\% \text { 9.5) }\end{array}$ \\
\hline $\begin{array}{l}\text { Kundmannia anatolica } \\
\text { Boiss. }\end{array}$ & Monoterpen & $\begin{array}{l}\beta \text { - Pinene } \\
(\% \text { 33.1) }\end{array}$ & $\begin{array}{c}\alpha \text {-Pinene } \\
(\% 27.9)\end{array}$ & $\begin{array}{l}\alpha \text {-Thujene } \\
(\% \text { 8.0) }\end{array}$ \\
\hline Pimpinella anisum L. & Fenol & $\begin{array}{l}\text { Anethole } \\
\text { (\% 90.3) }\end{array}$ & $\begin{array}{l}\text { Isoeugenol } \\
(\% 17.4)\end{array}$ & $\begin{array}{r}\text { Humulen } \\
(\% \text { 14.2) }\end{array}$ \\
\hline Scandix iberica Bieb. & Aldehit & $\begin{array}{l}\text { n-Undecanol } \\
(\% 25.0)\end{array}$ & $\begin{array}{l}\text { n-Tridecanel } \\
\text { (\% 14.7) }\end{array}$ & $\begin{array}{l}\text { Adacene } \\
\text { (\% 13.5) }\end{array}$ \\
\hline $\begin{array}{ll}\text { Smyrnium } & \text { connatum } \\
\text { Boiss\&Kotschy } & \\
\end{array}$ & Seskiterpen & $\begin{array}{l}\text { Curzerene } \\
(\% \text { 24.7) }\end{array}$ & $\begin{array}{l}\text { Germacrene D } \\
(\% \text { 17.8) }\end{array}$ & $\begin{array}{l}\text { Germacrane B } \\
(\% 13.0)\end{array}$ \\
\hline
\end{tabular}

\subsection{Araştırmada kullanılan uçucu yağların üretimi}

$\mathrm{Bu}$ çalışmada kullanılan bitkilere ait meyvelerin uçucu yağları Clevenger tipi hidro-distilasyon cihazı kullanılarak elde edilmiştir. Bu amaçla her türün meyvelerinden $100 \mathrm{~g}$ örnek ögütüldükten sonra 
distilasyon cihazının kaynatma balonunda $1 / 3$ oranında su eklenerek $100^{\circ} \mathrm{C}$ 'de 3 saat süreyle damitılmıştır (Marotti ve Piccaglia, 1992).

Her türe ait uçucu yağ örneklerinin bileşenleri GC - MS (Perkin Elmer marka) cihazında (QP5050 GC/MS, Quadrapole detektörlü) belirlenmiştir (Stein, 1990). Bu amaçla; n-hekzan seyreltilerek 1 $\mu 1$ kadar uçucu yağ silika kapiler kolona enjekte edilerek ve belirli bir çalışma proğramında (enjektör sicaklığ $1250^{\circ} \mathrm{C}$ de ve detektör sicaklığ $1240^{\circ} \mathrm{C}$ 'de tutularak, kolon/ firın sicaklığı ise $\left(120^{\circ} \mathrm{C} / 3\right.$ dak.// $3^{\circ} \mathrm{C} / \mathrm{dak} / / 200{ }^{\circ} \mathrm{C} / 6$ dak. $/ / 3^{\circ} \mathrm{C} /$ dak. $/ / 120^{\circ} \mathrm{C} / 3$ dak.) komponentlerine ayrilarak ve her bir komponent daha önce tanımlanmış olan uçucu yağ standart piklerinden oluşan kromatogramlar aracılığı tanımlanmıştır. Her bir komponentin oranı ise integratör kullanılarak elde edilmiştir (Stein, 1990). Uçucu yağların ana bileşenleri Çizelge 1 de verilmiştir.

\subsection{Kök lezyon nematodlarının kitle üretimi ve inokulumunun hazırlanması}

Kök lezyon nematodlarının kitle üretiminde havuç disk yönteminden yararlanılmıştır (Zuckerman ve ark., 1985). Taze ve hasarsız olan havuçlar seçilerek yıkanmış ve 5 dakika alkol içerisinde tutulmuştur. Daha sonra, steril kabinde soyulup yeniden alkol içerisine daldırılarak yüzey sterilizasyonu yapılmıştır. Havuçlar $1 \mathrm{~cm}$ kalınlığında kesilerek $6 \mathrm{~cm}$ çapında steril petriler içerisine alınmış ve etrafı parafilm ile kaplanmıştır. Steril kabin içerisinde 3 gün bekletilmiş ve temiz olanlar kitle üretim için kullanılmıştır. Canlı kök lezyon nematodları stereo mikroskop altında seçilerek saf su içeren bir petriye alındıktan sonra yüzey sterilizasyonu yapılmıştır. Bu amaçla nematodlar \% 1'lik Streptomycin sülfat çözeltisi ve penicilin içerisinde 10 dakika bekletilmiş ve sonra üç kez steril saf su ile yıkanmıştır. Steril kabin içerisinde yüzey sterilizasyonu yapılan nematodlardan 10-15 birey alınarak havuç kültürünün bulunduğu petriye aktarılmıştır. Bulaşmayı engellemek için parafilm ile kapatılmış ve $19-21^{\circ} \mathrm{C}$ 'de soğutmalı inkübatör içerisine yerleştirilmiştir. Yaklaşık 3 ayda nematodların istenilen yoğunluğa ulaştı̆̆ görülmüştür.

Denemeler için havuç kültürlerinden nematodları elde etmek amacıyla $12 \mathrm{~cm}$ çapında petrilere aktarılan havuç kültürü ince parçalar halinde kesilerek nematodların suya geçmesini sağlamak amacıyla üzerine yeterli miktarda steril saf su konulmuş ve 4-6 saat bekletilmiştir. Suya geçen nematodlar $38 \mu \mathrm{m}$ ve $20 \mu \mathrm{m}$ delik çapına sahip olan eleklerden geçirilerek santrifüj tüplerine alınmıştır. Bu şekilde kitle üretimi yapılan nematodlardan ışık mikroskobu altında sayımlar yapılarak 100 larva+ergin yoğunlukta olacak şekilde tüpler hazırlanmış ve inokulasyona hazır hale getirilmiştir.

\subsection{Uçucu yağların Kök lezyon nematodlarına karşı nematisidal etkilerinin belirlenmesi}

Çalışmada uçucu yağların nematisidal etkileri Pratylenchus thornei, $P$. penetrans ve $P$. neglectus larva+ergin bireylerinin hareket ve canlılığına dayanılarak in vitro koşullarda 3 tekrarlamalı olarak yürütülmüsstür. Her bir mikrotüp $(1.5 \mathrm{ml})$ içine otomatik pipet yardımıyla $50 \mu 1 \mathrm{saf}$ su ile birlikte 100 kök lezyon nematodu larva+ergin konulduktan sonra 1000 ppm konsantrasyonda olacak şekilde (Oka ve ark., 2000) uçucu yağ uygulamaları yapılmışıı. Uygulama tüp içerisindeki $50 \mu \mathrm{l}$ nematodlu su dahil konsantrasyon 1000 ppm olacak şekilde ayarlanmıştır. Her bir uçucu yağın 1000 ppm konsantrasyonu Tween-80 (\% 0.1) ve saf su kullanılarak hazırlanmıştır. Her bir tüp içerisine 950 $\mu \mathrm{l}$ uçucu yağ solüsyonu mikropipet yardımıyla konulmuştur. Çalışmada saf su ve Teween-80 uygulanan mikro tüpler kontrol olarak değerlendirilmiştir. Mikro tüpler parafilm ile kapatıldıktan sonra $25 \pm 1^{\circ} \mathrm{C}$ 'de tutularak 3 gün sonra mikroskop altında canlı-ölü birey sayımı yapılmış ve yüzde ölüm değerleri hesaplanmıştır (Oka ve ark., 2000).

Ölçüm ve analizler sonucu elde edilen veriler Tesadüf parselleri deneme planında faktöriyel düzenlemeye göre SAS (2009) istatistik paket programında GLM prosedürü kullanılarak standart varyans analizi tekniğinde (ANOVA) analiz edilmiş ve ortalamalar arasındaki farklılıklar LSD çoklu karşılaştırma testine göre belirlenmiştir.

\section{Bulgular}

Çalışmada uçucu yağlar, nematod türleri ve uçucu yağ x nematod interaksiyonu istatistiksel anlamda önemli bulunmuştur ( $\mathrm{p}<0.01)$ (Çizelge 2). 
Çizelge 2. Uçucu yağ uygulamalarının Kök lezyon nematodlarında ölüm oranına ilişkin varyans analiz sonuçları

\begin{tabular}{lccc}
\hline Varyasyon kaynakları & Serbestlik Derecesi & Kareler Ortalamas & F değerleri \\
\hline Uçucu yağlar (U) & 13 & 2957 & $594.4^{* *}$ \\
Nematod türleri (N) & 2 & 687 & $137.4^{* *}$ \\
U X N & 26 & 558 & $111.6^{* *}$ \\
Hata & 84 & 5.00 & \\
\hline
\end{tabular}

** İstatiksel olarak $\mathrm{P}<0.01$ düzeyinde önemlidir.

Pratylenchus neglectus türünde en yüksek nematisidal aktivite istatiksel olarak aynı grup içerisinde yer alan Coriondrum sativum (\% 64.7) ve Foeniculum vulgare (\% 63.3) uçucu yağlarından tespit edilmiştir (Çizelge 3). Heracleum platytaenium, Kundmannia anatolica ve Ferulago pauciradiata türlerinin uçucu yağları mevcut $P$. neglectus popülasyonunun yaklaşık olarak \% 50 sinde nematisidal etki göstermiştir (Çizelge 3). Pratylenchus neglectus üzerinde Pimpinella anisum, Smyrnium connatum, Angelica sylvestris, Ferulago cassia, Daucus carota, Scandix iberica ve Anethum graveolens türlerinin uçucu yağları diğer uçucu yağlara göre daha düşük nematisidal etkiye sahip olmuştur (Çizelge 3). Saf su uygulamalarında meydana gelen ölümlerin nematodların aç kalma ihtimalinden kaynaklandığ 1 düşünülmektedir. Saf suya karşı Tween-80'de meydana gelen ölümlerin fazla olduğu görülmektedir. Bunun Tween-80'nin doku yüzeylerini yumuşatarak hücre içerisindeki sıv1 dengesinin bozulmasından kaynaklandığı düşünülmektedir (Çizelge 3). Kontrole kıyasla P.penetrans türünde popülasyonun \% 50 den fazlasının ölümüne neden olan uçucu yağlar $F$. vulgare, A. graveolens, A. sylvestris, $H$. platytaenium, C. sativum ve $S$. connatum tespit edilmiştir (Çizelge 3 ). Pratylenchus penetrans türünde nematisidal etkisi \% 30'un altında olan tek uçucu yağ K. anatolica olarak saptanmıștır (Çizelge 3). Pratylenchus thornei popülasyonunun \% 70 den fazlasını öldüren 3 uçucu yağ F. cassia (\% 85.0), A. sylvestris (\% 78.0) ve C. sativum (\% 75.0) olarak belirlenmiştir (Çizelge 3). Bunun yanısıra K. anatolica (\% 61.7), S. connatum (\% 50.0) ve P. anisum (\% 50.3) uçucu yağlarının $P$. thornei popülasyonunun yarısına yakın bir kısmı üzerinde nematisidal etki gösterdiği belirlenmiştir (Çizelge 3). Ferulago pauciradiata, F. vulgare, D. carota, A. graveolens, S. iberica ve $H$. platytaenium türlerine ait uçucu yağlar kontrol gruplarına göre $P$. thornei üzerinde nematisidal etki göstermesine karşı1ık araştırmada kullanılan diğer uçucu yağlardan daha düşük nematisidal etkiye sahip olmuştur (Çizelge 3).

Çizelge 3. Çalışmada kullanılan uçucu yağların Kök lezyon nematodlarında ( $P$. neglectus, $P$. penetrans ve $P$. thornei) ölüm oranları (\%)

\begin{tabular}{lccc}
\hline \multirow{2}{*}{ Uçucu yağlar } & & Ölüm Orani (\%) & \\
\cline { 2 - 4 } & P. neglectus & P.penetrans & P. thornei \\
\hline AS & 64.7 a B & $57.0 \mathrm{c} \mathrm{C}$ & $75.0 \mathrm{~b} \mathrm{~A}$ \\
FC & $37.7 \mathrm{~d} \mathrm{C}$ & $63.7 \mathrm{~b} \mathrm{~B}$ & $78.0 \mathrm{~b} \mathrm{~A}$ \\
FV & $36.0 \mathrm{~d} \mathrm{C}$ & $51.7 \mathrm{~d} \mathrm{~B}$ & $85.0 \mathrm{a} \mathrm{A}$ \\
HP & $63.3 \mathrm{a} \mathrm{B}$ & $69.0 \mathrm{a} \mathrm{A}$ & $33.7 \mathrm{f} \mathrm{C}$ \\
SC & $54.0 \mathrm{~b} \mathrm{~A}$ & $58.3 \mathrm{c} \mathrm{A}$ & $35.3 \mathrm{f} \mathrm{B}$ \\
AG & $41.3 \mathrm{c} \mathrm{B}$ & $51.3 \mathrm{~d} \mathrm{~A}$ & $50.0 \mathrm{~d} \mathrm{~A}$ \\
PA & $24.3 \mathrm{f} \mathrm{C}$ & $66.7 \mathrm{ab} \mathrm{A}$ & $47.3 \mathrm{de} \mathrm{B}$ \\
KA & $42.3 \mathrm{c} \mathrm{B}$ & $45.3 \mathrm{e} \mathrm{AB}$ & $50.3 \mathrm{~d} \mathrm{~A}$ \\
FP & $52.7 \mathrm{~b} \mathrm{~B}$ & $23.7 \mathrm{~h} \mathrm{C}$ & $61.7 \mathrm{c} \mathrm{A}$ \\
DC & $52.0 \mathrm{~b} \mathrm{~A}$ & $39.3 \mathrm{f} \mathrm{B}$ & 44.0 e B \\
SI & $31.7 \mathrm{e} \mathrm{C}$ & $36.7 \mathrm{fg} \mathrm{B}$ & $46.3 \mathrm{de} \mathrm{A}$ \\
TW & $26.0 \mathrm{f} \mathrm{B}$ & $34.0 \mathrm{~g} \mathrm{~A}$ & $33.7 \mathrm{f} \mathrm{A}$ \\
SAFSU & $8.3 \mathrm{~g} \mathrm{~A}$ & $9.0 \mathrm{~A}$ & $5.3 \mathrm{~g} \mathrm{~B}$ \\
Lsduxn & $3.0 \mathrm{~h} \mathrm{AB}$ & $2.0 \mathrm{j} \mathrm{B}$ & $3.7 \mathrm{~g} \mathrm{~A}$ \\
\hline
\end{tabular}

Küçük harflerle yapılmış olan gruplandırma nematodxuçucu yağ, Büyük harfler ile yapılan gruplandırma ise uçucu yağ $\mathrm{x}$ nematod interaksiyonuna aittir. 


\section{Tartışma ve Sonuç}

Uçucu yağların nematisidal etkileri Kök lezyon nematodu türüne bağlı olarak değişiklik göstermiştir ve ölüm oranları Pratylenchus neglectus türünde \% 24.3-64.7, P . penetrans türünde \% 23.7-66.7 ve $P$. thornei türünde \% 33.7-85.0 arasında değişim göstermiştir. Pratylenchus thornei türünün diğer nematod türlerine oranla uçucu yağ uygulamalarına karşı daha yüksek hassasiyet gösterdiği saptanmıştır (Çizelge 3). Bu durum Kök lezyon nematodu türlerinin üreme şekli ve üreme gücü farklılığından kaynaklanabilir. Pratylenchus türlerinin çoğunda parthenogenesis yoluyla üreme görülürken, $P$. penetrans türünde seksüel üreme görülmektedir (Castillo ve Vovlas, 2007). Ayrıca daha önce yürütülen çalışmalarda aynı türün popülasyonları arasında bile patojenite açısından biyolojik çeşitliliğin olduğu $P$. brachyurus (Payan ve Dickson, 1990), $P$. goodeyi ve $P$. penetrans (Hafez ve ark., 1999) ve P. vulnus (Pinochet ve ark., 1994) türlerinde bildirilmektedir. Bu duruma örneklerin alındığı coğrafik alanlar ve bu alanlardaki toprak yapısı, bitki faktörleri vs. gibi farklılıkların etkili olduğu ve patojenitenin değişebildiği belirtilmektedir (Mudiope ve ark., 2004). Nematod türlerinin kütikula geçirgenliğinin uçucu yağ bileşiklerinin penetrasyonunu etkilediği ve nematod türleri arasındaki biyokimyasal farklılıkların bu bileşiklerin detoksifikasyonuna ya da bozulmasına neden olarak uçucu yağ bileşenlerinin nematisidal aktivitesini azalttı̆̆ 1 bildirilmiştir (Tsoo ve Yu, 2000).

Çalışmada Coriondrum sativum'un nematisidal etkisi 3 Kök lezyon nematodu türünde \% 50'nin üzerinde saptanmıştır (Çizelge 3). Bu linaool bileşiğinin tek başına etkisinden olabileceği gibi uçucu yağ içerisindeki diğer bileşenlerle olan sinerjistik etkiden de kaynaklanabilir (Çizelge 1). Daha önce yürütülen çalışmalarda C. sativum uçucu yağının Bursephelenchus xylophilus Steiner \& Buhrer 1934, Nickle, 1970 ve Meloidogyne javanica nematodları üzerinde nematoksik etkisi olduğu tespit edilmiştir (Kong ve ark., 2006; Kim ve ark., 2008; Siddiqui ve Zaki, 2017). Ayrıca methone ve linalool bileşiklerinin $M$. javanica, $M$. incognita ve B. xylophilus nematodlarına karş1 etkili olduğu bildirilmektedir (Oka ve ark., 2000; Ibrahim ve ark., 2006; Barbosa ve ark., 2010). Liang ve ark. (2020), Elsholtzia fruticosa üst aksamından elde ettikleri uçucu yağın 3 ana bileşeni olan limonen, okaliptol ve terpinenin Ditylenchus destructor nematodu üzerinde nematisidal etkisi olduğunu saptamışlardır.

Angelica sylvestris uçucu yağının ise Pratylenchus penetrans ve $P$. thornei üzerinde nematisidal etkisi \% 60'dan yüksek bulunmuştur (Çizelge 3). Bu uçucu yağın daha önce in vitro da Meloidogyne incognita üzerinde yürütülen çalışmada da yüksek nematisidal etki gösterdiği tespit edilmiştir (Göze Özdemir ve ark., 2017).

Çalışmada etkisi yüksek bulunan Ferulago cassia ve Foeniculum vulgare uçucu yağlarının ortak bileşenlerinin ise limonen olduğu görülmektedir (Çizelge 1). Citral, geraniol ve limonenin toprak uygulamalarının Meloidogyne javanica, M. incognita ve Heterodera schachtii bitki paraziti nematodlarının çoğalmasını engellediği daha önce araştırıcılar tarafından bildirilmiştir (Osman ve Viglierchio, 1988; Viglierchio, 1989; Bauske ve ark., 1994). Duschatzky ve ark. (2004), Aloysia triphylla bitkisinden elde edilen uçucu yağın kök-ur nematodu larvalarının \% 80 den fazlasını öldürdügünü ve uçucu yağdaki ana bileşeni limonene olarak tespit etmişlerdir. Ayrıca F. vulgare uçucu yağının $P$. brachyurus ve $M$. javanica üzerinde yüksek nematisidal aktiviteye sahip olduğu belirtilmektedir (Oka ve ark., 2000; Calvet ve ark., 2001; Ntalli ve ark., 2011; Marie ve ark., 2015).

Çalışmada ele alınan uçucu yağlardan seskiterpenoid bakımdan zengin olan $S$. connatum ve $D$. carota'nın, monoterpenoidler bakımdan zengin olan F. vulgara, F. cassia, C. sativum, A. sylvestris ve A. graveolens uçucu yağlarından daha düşük nematisidal etkiye sahip oldukları belirlenmiştir. Ayrıca çalışmada pinene içeriği bakımından yüksek olan $K$. anatolica 'nın nemotisidal etkisinin nematod tür bazında değiştiği ve diğer monoterpen içeren türlere oranla nematisidal etkisinin daha düşük olduğu bulunmuştur. $\mathrm{Bu}$ durum uçucu yağın içermiş olduğu diğer bileşenlerin antigonistik etki göstermesinden kaynaklanmış olabilir. Monoterpenler ve fenilpropenler, seskiterpen ve alkollere kıyaslandığında asetilkolinesteraz aktivitesi üzerindeki inhibitör etkisi ile güçlü bir nematisidal aktivite gösterdiği bildirilmiştir (Lee ve ark., 2001; El-Habashy ve ark., 2020). Monoterpenoid grubunda yer alan $\alpha$-pinene, $\alpha$-terpinene ve eugenol bileşiklerinin asetilkolinesteraz aktivitesinin önemli ölçüde inhibe edilmesine neden olduğu belirtilmektedir (Saad ve ark., 2018). İkiyüz elli $\mathrm{mg} / \mathrm{ml}$ konsatrasyonunda monoterpenoid grubundaki çoğu bileşiğin $P$. penetrans üzerine ticari nematisit Oxamyl’ den daha fazla toksik etki gösterdiği bildirilmiştir (Tsoo ve Yu, 2000). 
$\mathrm{Bu}$ çalışma nematisidal etkinin, aktif bileşenlerin türü ve içeriğine bağlı olarak nematod türleri içerisinde değiştiğini ve monoterpenlerin Kök lezyon nematodlarına karşı potansiyel doğal nematisit kaynağı olduğunu göstermiştir. Linalool ve limonen bileşiklerini içeren uçucu yağların ise nematisidal etkisinin daha yüksek olduğu tespit edilmiştir. Bu durum bu bileşenlerin uçucu yağlar içerisindeki diğer bileşenlerle sinerjistik etkisinden de kaynaklanabilmektedir. Sonuç olarak, Coriondrum sativum, Angelica sylvestris, Ferulago cassia ve Foeniculum vulgare uçucu yağlarının Kök lezyon nematodları ile mücadelede doğal nematisit olarak kullanılabileceği, bununla birlikte daha gerçekçi sonuçlara ulaşabilmek için bu uçucu yağların farklı konsantrasyonlarda arazi koşullarında denenerek performanslarının ve bitki gelişimine etkilerinin belirlenmesi gerekmektedir.

\section{Teşekkür}

$\mathrm{Bu}$ çalışmada materyal olarak kullanılan uçucu yağlar TÜBİTAK $113 \mathrm{O} 284$ nolu projeden temin edilmiştir. TÜBİTAK $113 \mathrm{O} 284$ nolu projeye desteklerinden dolayı teşekkür ederiz.

\section{Kaynakça}

Andres M., Gonzalez-Coloma A., Sanz J., Burillo J., \& Sainz P. (2012). Nematicidal activity of essential oils: a review Phytochemistry Review DOI 10.1007/s11101-012-9263-3.

Avato, P., Laquale, S., Argentieri, M. P., Lamiri, A., Radicci, V., \& D’Addabbo, T. (2017). Nematicidal activity of essential oilsfrom aromatic plants of Morocco. Journal of pest science, 90(2), 711-722.

Barbosa P., Lima A. S., Vieira P., Dias L. S., Tinoco M. T., \& Barroso J. G. (2010). Nematicidal activity of EOs and volatiles derived from portuguese aromatic flora against the pinewood nematode, Bursaphelenchus xylophilus. J Nematol 42, 8-16.

Bauske E. M., Rodr'1guez-Ka'bana R., Estau'n V., Kloepper J. W., \& Robertson D. G. (1994). Management of Meloidogyne incognita on cotton by use of botanical aromatic compounds. Nematropica, 24, 143-50.

Blair, B. L. \& Stirling, G. R. (2007). The role of plant-parasitic nematodes in reducing yield of sugarcane in fine-textured soils in Queensland, Australia. Australian Journal of Experimental Agriculture, 47(5), 620-634.

Calvet C., Pinochet J., Camprubi A., Estaun V., \& Rodriquez-kabana R. (2001). Evaluation of natural chemical compounds against root lesion and root knot nematodes and side effects on the infectivity of arbuscular mycorrhizal fungi. European Journal of Plant Pathology, 107, 601605.

Castillo P., \& Vovlas N. (2007). Pratylenchus (Nematoda: Pratylenchidae): Diagnosis, Biology, Pathogenicity and Management. Nematology Monographs and Perspectives Volume 6.

Cavanagh, H., \& M., A. (2007). Antifungal activity of the volatile phase of essential oils: A brief review, Nat. Prod. Commun, 2, 1297-1302.

Dorman, H., J., D., \& Deans, S.G. (2000). Antimicrobial agents from plants: antibacterial activity of plant volatile oils, Journal of Applied Microbiology, .88, 308-316.

Duschatzky, C. B., Martinez, A. N., Almeida, N. V., \& Bonivardo, S. L. (2004). Nematicidal activity of the essential oils of several Argentina plants against the root-knot nematode. Journal of Essential Oil Research, 16(6), 626-628.

El-Habashy, D. E., Abdel Rasoul, M. A., \& Abdelgaleil, S. A. M. (2020). Nematicidal activity of phytochemicals and their potential use for the control of Meloidogyne javanica infected eggplant in the greenhouse. European Journal of Plant Pathology. doi:10.1007/s10658-02002079-6.

Figueiredo, A. C., Barroso, J. G., Pedro, L. G., \& Scheffer, J. J. (2008). Factors affecting secondary metabolite production inplants: volatile components and essential oils. Flavour and Fragrance journal, 23(4), 213-226.

Gupta A., Sharma S., \& Naik S.N. (2011). Biopesticidal value of selected EOs against pathogenic fungus, termites, and nematodes. International Biodeterioration Biodegradation, 65, 703-707. 
Hafez, S. L., Al-Rehiayan1, S., Thornton, M. \& Sundararaj, P. (1999). Differentiation of two geographically isolated populations of Pratylenchus neglectus based ontheir parasitism of potato and interactionwithVerticilliumdahliae. Nematropica 29, 25-36.

Jones, M. G. K. \& Fosu-Nyarko, J. (2014). Molecular biology of root lesion nematodes (Pratylenchus spp.) and their interaction with host plants. Annals of applied biology,164(2), 163-181.

Kim, S. S., Baik, J. S., Oh, T. H., Yoon, W. J., Lee, N. H., \& Hyun. C. G. (2008). Biological activities of Korean Citrus obovoides and Citrus natsudaidai essential oils against acne-inducing bacteria. Biosci Biotechnol Biochem 72, 2507-2513

Kong J., Lee S., Moon Y., Lee S., \& Ahn Y. (2006). Nematicidal activity of plant EOs against Bursaphelenchus xylophilus (Nematoda: aphelenchoididae). Journal of Asia Pacific Entomology, 9,173-178.

Lang, G., \& Buchbauer, G. (2012). A review on recent research results (2008-2010) on essential oils as antimicrobials and antifungals, Flavour Fragr. J., 27, 13-39.

Lee H. S., (2006). Mosquito larvicidal activity of aromatic medicinal plant oils against Aedes aegypti and Culex pipiens pallens. Journal of the American Mosquito Control Association, 22, 292295.

Liang, J. Y., Ning, A. Q., Lu, P. Y., Shao, Y. Z., Xu, J., Yang, Y. Y., \& Wang, H. L. (2020). Chemical Composition and BiologicalActivity of Essential Oil Extracted from the Aerial Part of Elsholtzia fruticosa against Ditylenchus destructor. Journal of Essential Oil Bearing Plants, 23(3), 575-582.

Marotti M., \& Piccaglia R. (1992). The Influence of Distillation Conditions on the Essential Oil Composition of Three Varieties of Foeniculum vulgare Mill. Journal of Essential Oil Research, 4, 569-576.

Mudiope, J., Adipala, E., Coyne, D., \& Sikora, R. (2004). Monoxenic culture of Pratylenchus sudanensis on carrot disks, with evidence of differences in reproductive rates between geographical isolates. Nematology, 6(4), 617-619.

Ntalli N. G., Ferrari F., Giannakou I., \& Menkissoglu-Spiroudi U. (2011). Synergistic and antagonistic interactions of terpenes against Meloidogyne incognita and the nematicidal activity of EOs from seven plants indigenous to Greece. Pest Management Science 67, 341-351.

Ntalli, N., G., Ferrari, F., Giannakou, I., \& Menkissoglu-Spiroudi, U. (2010). Phytochemistry and nematicidal activity of the essential oils from 8 Greek Lamiaceae aromatic plants and 13 terpene components, J. Agric. Food Chem., 58, 7856-7863.

Oka Y., Nacar S., Putievsky E., Ravid U., Yaniv Z., \& Spiegel Y. (2000). Nematicidal activity of EOs and their components against the root-knot nematode. Phytopathology, 90, 710-715.

Osman A.A., \& Viglierchio D.R. (1988). Efficacy of biologically active agents as non traditional nematicides for Meloidogyne javanica. Review of N'ematology,11, 93-98.

Payan, L. A., \& Dickson, D. W. (1990). Comparison of populations of Pratylenchus brachyurus based on isozyme phenotypes. Journal of Nematology, 22(4), 538.

Pinochet, P., Cenis, J. L., Fernandez, C., Doucet, M., \& Maruli, J. (1994). Reproductive fitness and random amplified polymorphic DNA variation among isolates of Pratylenchus vulnus. Journal of Nematology, 26(3), 271.

Renco M., \& Balezentiene L. (2015). An analysis of soil free-living and plant-parasitic nematode communities in three habitats invaded by Heracleum sosnowskyi in central. Biol Invasions, 17, 1025-1039.

Saad, M. M. G., Abou-Taleb, H. K., \& Abdelgaleil, S. A. M. (2018). Insecticidal activities of monoterpenes and phenylpropenes against Sitophilus oryzae and their inhibitory effects on acetylcholinesterase and adenosine Eur J Plant Pathol triphosphatases. Applied Entomology and Zoology, 53(2), 173-181.

Siddiqui A., \& Zaki M. J. (2017). Efficacy of some seeds of family apiaceae against root knot nematode, meloidogyne javanica (treub) chitwood. Internatıonal Journal of Blology and Biotechnology, 14 (1), 89-94.

Smiley R.W., \& Nicol J. M., (2009). Nematodes Which Challenge Global Wheat Production. In: Carver B.F. (ed.) Wheat science and trade, Wiley-Blackwell, pp. 171-187.

Söğüt M. A., \& Devran Z. (2011). Distribution and molecular identification of root lesion nematodes in temperate fruit orchards of Turkey. Nematropica, 41, 91-99. 
Stein S. E., 1990. National Institute of Standardsand Technology (NIST) Mass Spectral Database and Software, Version 3.02, Juen USA.

Tsao R., \& Yu Q. (2000). Nematicidal Activity of Monoterpenoid Compounds against Economically Important Nematodes in Agriculture. Journal of Essential Oil Research, 12, 3, 350-354.

Viglierchio D.R., \& Wu F.F., 1989. Selected biological inhibitors for Heterodera schachtii control. Nematropica, 19, 75-79.

Zuckerman B. M., Mai W. F., \& Harrison M. B. (1985). Plant Nematology Laboratory Manual. The University of Massachusetts Agricultural Experiment Station Amherst, Massachusetts 01003, Pp: 212 